\title{
Templating core-shell particles using metal ion-chelating biosurfactants
}

Ching-min Yeh $^{1,2}$; Thomas Jarrett ${ }^{1}$; Yuan Gao ${ }^{1}$; Chun-Xia Zhao ${ }^{1}$; Andrew Whittaker ${ }^{1,2}$, Frank Sainsbury ${ }^{1,4 *}$; Alison L. White ${ }^{1,2,3 *}$

1. Australian Institute of Bioengineering and Nanotechnology, The University of Queensland, St. Lucia, Queensland, 4072, Australia.

2. ARC Centre of Excellence in Convergent Bio-Nano Science and Technology, The University of Queensland, St Lucia, 4072, Australia

3. CSIRO Probing Biosystems Future Science Platform, Brisbane, Australia

4. Centre for Cell Factories and Biopolymers, Griffith Institute for Drug Discovery, Griffith University, Brisbane, QLD, 4111 Australia

*Correspondence: a.tasker@uq.edu.au, f.sainsbury@griffith.edu.au

\begin{abstract}
Designer biosurfactants can be used to stabilise and functionalise interfaces. One particularly promising use is the stabilisation of oil-in-water emulsions, enabling fine tuning physical, chemical and biological surface properties. The ability of emulsion systems to carry high payloads makes them attractive for applications in medicine, food and fragrances, and cosmetics. However, they have limited long-term stability. Here we sought to use the metal ion-chelating ability of the biosurfactant peptide, AM1, to precipitate the formation of a gold metal shell on AM1-stabilised emulsions by electroless plating. We found that replacing the commonly used zinc(II) with palladium(II) for coordination by histidine residues of adjacent AM1 peptides produced interfacial films that maintained elasticity at acidic $\mathrm{pH}$. Proton NMR suggested a coordination mechanism independent of the imidazole ring of the histidines. Nevertheless. stabilisation of emulsions at low $\mathrm{pH}$ enabled the deposition of a gold shell, albeit by an unexpected mechanism. We propose that gold nanoparticles forming in bulk are adsorbed onto the peptide-stabilised interface, accumulating into a particulate coating. The resulting one-step method for nanoparticle precipitation and shell formation will be useful for the creation of biocompatible core-shell particles for applications where large payloads of hydrophobic active compounds require stability over long time periods.
\end{abstract}

\section{Keywords}

Biosurfactants; emulsion; core-shell particles; electroless plating; histidine; interfacial elasticity 


\section{INTRODUCTION}

The production of stable nanoscale emulsions provides an opportunity to design simple carriers of lipophilic materials for biomedical applications such as drug delivery (Tayeb \& Sainsbury, 2018), molecular imaging (Rosenblum, Kosaka, Mitsunaga, Choyke, \& Kobayashi, 2010; Simms, et al., 2012), vaccines (Leleux \& Roy, 2013) and improved shelflife for food products (Velikov \& Pelan, 2008) and cosmetics (Sonneville-Aubrun, Yukuyama, \& Pizzino, 2018). Nanoemulsions, kinetically stable yet thermodynamically unstable emulsions with an upper size limit of $200 \mathrm{~nm}$ (Mason, Wilking, Meleson, Chang, \& Graves, 2006), although sometimes defined as having an upper limit of $1000 \mathrm{~nm}$ (Sainsbury, Zeng, \& Middelberg, 2014; Sonneville-Aubrun, et al., 2018), have recently gained attention due to their capacity to dissolve large quantities of poorly water-soluble therapeutics (Sainsbury, et al., 2014; Tayeb \& Sainsbury, 2018), with potential biocompatibility and templating opportunities for stabilising shells (Mason, et al., 2006). The advantages of their small size and surface modification opportunities makes them ideal candidates for use as delivery vehicles that protect encapsulated material from hydrolysis, oxidation and enzymatic degradation, and allow for controlled or targeted delivery.

Biosurfactants, in particular, short peptide surfactants, specifically designed for self-assembly at air-water or oil-water interfaces, provide an opportunity for the development of biocompatible delivery vehicles for active ingredients (Chuan, Zeng, O'Sullivan, Thomas, \& Middelberg, 2012; Dexter \& Middelberg, 2008; Malcolm, Dexter, \& Middelberg, 2007; Sainsbury, et al., 2014). Genetic or chemical functionalisation of designer biosurfactants enables the surface presentation of targeting moieties (Tayeb, et al., 2017; Zeng, et al., 2013) tuneable surface charge (Tayeb, Stienecker, Middelberg, \& Sainsbury, 2019; Yamada, et al., 2018), and modification of interfacial viscoelasticity (Gao, Zhao, \& Sainsbury, 2021). A designer 21-residue amphiphilic peptide, AM1 (Ac-MKQLADS LHQLARQ VSRLEHACONH2), derived from the helix-forming sequence of Lac21 (Dexter \& Middelberg, 2007, 2008) self-assembles into a stimuli-responsive material upon rapid adsorption at the oil/water interface, to give emulsions with a narrow size distribution (Malcolm, et al., 2007). This peptide was specifically designed so that its hydrophobic residues align at the interface when in the $\alpha$-helical conformation, with two histidine groups in the aqueous phase, directed towards neighbouring peptide chains. It has been proposed that the two metal-binding histidine residues cross-link adjacent adsorbed AM1 peptides via coordination to divalent 
zinc ions (Dexter \& Middelberg, 2007). DAMP4 is a derivative of AM1, consisting of four repeating units of AM1 linked by the sequence Asp-Pro-Ser (Middelberg \& DimitrijevDwyer, 2011). Emulsions stabilised with DAMP4-Zn(II) have been reported to remain stable to coalescence for over 30 days, producing an interfacial network with increased mechanical resistance as compared to that formed by AM1-Zn(II) (Dimitrijev-Dwyer, et al., 2012) enabling their use in more demanding applications (Sainsbury, et al., 2014).

One of the greatest challenges when using emulsions as an encapsulation vehicle is achieving long-term containment of core materials, preventing leakage to the external environment. Liquid particles can be especially difficult as they are prone to irreversible destabilisation by phenomena such as Oswald ripening, coalescence and aggregation (Nocera, et al., 2014). Addition of an inorganic shell or coating around the outside of emulsion droplets has the potential to overcome both the issues of stability and undesired release. Various metals and metal oxides have been successfully deposited onto emulsion templates, but these typically involve multiple steps to activate the droplet surface before the shell can be deposited (Nocera, et al., 2014). Continuous gold shells can also be grown at the oil-water interface of a Pickering emulsion where platinum nanoparticles are used both as the Pickering stabiliser and to catalyse the gold reduction and deposition (Stark, et al., 2019; White, et al., 2019). Such gold coated emulsions have been prepared over a size range spanning from $100 \mathrm{~nm}$ to over 10 $\mu \mathrm{m}$ (Hitchcock, et al., 2019) and have been shown to prevent any release of the encapsulated ingredient until rupture by an external trigger.

Wibowo et al. recently demonstrated that peptide stabilised emulsions could be coated with a silica shell of tuneable thickness to allow for sustained release of an active ingredient (Wibowo, Zhao, \& Middelberg, 2014). The use of a modified AM1 peptide for biosilicification demonstrated that oil-water interfaces can be sufficiently stabilised by designer biosurfactants to permit mineralisation at the interface under relatively benign conditions. The aim of this work is to design a biocompatible, emulsion-based delivery vehicle with enhanced stability derived from a gold shell. We hypothesise that by replacing the divalent $\mathrm{Zn}$ (II) ions used to cross-link peptides at the oil-water interface with a known catalyst for electroless deposition, a gold shell could be deposited on the droplet surface to enhance the stability of the emulsion and retention of cargo. 


\section{MATERIALS AND METHODS}

\section{Materials}

AM1 (MW 2473) custom synthesized by GenScript Corporation (Piscataway, NJ). The purity of lyophilized AM1 was $>95 \%$ by reversed-phase high performance liquid chromatography (RP-HPLC). Miglyol812® was a gift from IOI Oleo GmbH (Hamburg, Germany). Zinc chloride $\left(\mathrm{ZnCl}_{2}\right)$ 98\%; palladium chloride $\left(\mathrm{PdCl}_{2}\right)$ 99.9\%; chloroauric acid $\left(\mathrm{HAuCl}_{4}\right)$ 99.99\%; poly(vinyl pyrrolidone) (PVP) (40 kDa); 35\% hydrogen peroxide $\left(\mathrm{H}_{2} \mathrm{O}_{2}\right)$; ethylenediaminetetraacetic acid (EDTA); ethanol; deuterium oxide $\left(\mathrm{D}_{2} \mathrm{O}\right)$ were purchased from Sigma-Aldrich. Ultra-pure water was used for all experiments (Milli-Q, Millipore, North Ryde, Australia) dispensed through a $0.22 \mu \mathrm{m}$ filter, with a resistivity of $>18.2 \mathrm{M} \Omega$ $\mathrm{cm}$.

\section{DAMP4 expression and purification}

DAMP4 was expressed and purified from Escherichia coli cells as previously described (Middelberg \& Dimitrijev-Dwyer, 2011; Tayeb, et al., 2017). Briefly, immobilized metal affinity chromatography was used to enrich the metal-binding DAMP4 via 8 histidine residues. Charged contaminants were removed by sequential cation and anion exchange chromatography and the aliphatic DAMP4 was polished and concentrated by reversed phase chromatography.

\section{Peptide-stabilised emulsions}

AM1 or DAMP4 stabilised Miglyol812 oil-in-water emulsions were synthesised as follows. AM1 solution $(200 \mu \mathrm{M})$ was prepared by dissolving lyophilized AM1 in ultrapure water (Milli-Q) as continuous phase for the emulsions. $\mathrm{ZnCl}_{2}$ (or $\mathrm{PdCl}_{2}$ or $\left.\mathrm{PtCl}_{2}\right)(400 \mu \mathrm{M}$ ) was added to the solution for coordination to AM1 at the interface, and gently mixed at room temperature for 5 minutes. Miglyol812 (2\% v/v) was added, then emulsified using Brandon Sonifier 450 Ultrasonicator for 4 x 30s bursts at approximately $20 \mathrm{~W}$, resting in ice for at least 1-minute between each burst. Peptide-stabilised emulsions were dialysed using Thermo Scientific SnakeSkin Dialysis Tubing 10K MWCO in ultrapure water (1:500) at room temperature, to remove excess metal ions and AM1. To investigate the effect of peptide concentration on emulsion size, concentrations of $10,50,100,200$ and $400 \mu \mathrm{M}$ were used. 


\section{Electroless deposition of gold onto emulsion surfaces}

A gold plating solution was prepared, first by mixing the AM1-stabilised emulsion dispersion $(0.5 \mathrm{~mL})$ with PVP $(0.02 \mathrm{wt} \%)$ and $\mathrm{H}_{2} \mathrm{O}_{2}(12 \mathrm{mM})$ for 5 minutes at room temperature, then $\mathrm{HAuCl}_{4}(8 \mathrm{mM})$ was slowly added over 1 minute to reduce nanoparticle formation in solution. Samples were washed using dialysis (Thermo Scientific SnakeSkin Dialysis Tubing $10 \mathrm{~K}$ MWCO) for 2 hours in 1:500 water at room temperature.

\section{Dynamic Light Scattering (DLS)}

The size and zeta potential of emulsions were characterized using dynamic light scattering (DLS) using Malvern Zetasizer Nano ZS (Malvern, Worcestershire, UK). Emulsions were diluted 1/100 into ultrapure water prior to analysis to avoid multiple scattering effects. Data analysis was processed using the DTS Zetasizer software (Malvern, version 4.2). Dispersant (ultrapure water) refractive index and viscosity were assumed to be 1.330 and $0.8872 \mathrm{cP}$, respectively.

\section{Drop Shape Analysis (DSA)}

The contraction of oil droplets was observed using a Krüss Drop Shape Analysis System, DSA-10 (Krüss GmbH, Hamburg, Germany). A solution of AM1 $(100 \mu \mathrm{M})$ and $\mathrm{ZnCl}_{2}(200$ $\mu \mathrm{M})$ in MilliQ water was loaded into an $8 \mathrm{~mL}$ quartz cuvette. Miglyol812 oil droplets (approximately $10 \mu \mathrm{L}$ ) were manually formed in the solution from a U-shaped stainless steel capillary of known diameter $(1.5 \mathrm{~mm})$, attached to a glass syringe. Droplets were left undisturbed for 30 minutes. Qualitative elasticity of the droplet interface were observed by a fast contraction (to around 2-3 $\mu \mathrm{L}$ for droplet volume), determined by the presence of 'wrinkles'. To investigate the effect of $\mathrm{pH}$ on droplet elasticity, contractions were performed under different $\mathrm{pH}$, monitored by addition of $\mathrm{HCl}$ or $\mathrm{NaOH}$. Droplet contractions were repeated with $\mathrm{AM} 1$ alone, $\mathrm{PtCl}_{2}, \mathrm{PdCl}_{2}$ to substitute $\mathrm{ZnCl}_{2}$, under different $\mathrm{pH}$ conditions, along with controls of water, AM1 solution, and metal chloride solution.

\section{Cambridge Interfacial Tensiometer (CIT)}

A PTFE trough $\left(80 \times 20 \times 3 \mathrm{~mm}^{3}\right)$ supplied by Nima Technology Ltd (Conventry, U.K.) is used for the CIT. The trough was cleaned between samples by extensive rinsing with $5 \mathrm{mM}$ $\mathrm{Na}^{+}$EDTA ( $\mathrm{pH} \mathrm{10),} \mathrm{50v/v \%} \mathrm{ethanol,} \mathrm{and} \mathrm{Milli-Q} \mathrm{water.} \mathrm{Test} \mathrm{solutions} \mathrm{(6.5} \mathrm{mL)} \mathrm{were} \mathrm{filled}$ 
in the trough, forming a meniscus above which floated two fiber optic T-pieces (initial separation $1000 \mu \mathrm{m}$ ) attached to a piezoelectric motor and a highly sensitive force transducer, respectively. The trough was loaded with an AM1 solution consisting of AM1 (20 $\mu \mathrm{M})$ and $\mathrm{ZnCl}_{2}(40 \mu \mathrm{M})$ in ultrapure water at $\mathrm{pH}$ 7.4. Tension-compression cycles of the motor $\mathrm{T}$ piece was used to add strain to the film up to $300 \%$, in order to characterise the response of the surfactant film to high strain. The interfacial stress transmitted was registered via the Tpiece connected to the force transducer. Similar to the drop contraction experiment, effect of $\mathrm{pH}$ and $\mathrm{PdCl}_{2}$ were also studied using the CIT. The elasticity modulus (E) was calculated from the gradient of the linear line of best fit on the plot of the interfacial stress $\left(\mathrm{mN} \mathrm{m}^{-1}\right)$ versus strain from $0 \%$ to $5 \%$.

\section{Nuclear Magnetic Resonance (NMR)}

A series of solution of metal chloride ( $\mathrm{Zn}(\mathrm{II})$ or $\mathrm{Pd}(\mathrm{II})$ ) in histidine were prepared by adding appropriate amounts of $\mathrm{ZnCl}_{2}\left(0\right.$ to $184 \mathrm{mM}$ in $\left.\mathrm{D}_{2} \mathrm{O}\right)$ to L-Histidine $\left(92 \mathrm{mM}\right.$ in $\left.\mathrm{D}_{2} \mathrm{O}\right)$ so that resulting solutions had $\mathrm{Zn}(\mathrm{II}) / \mathrm{His}$ molar ratio varying from $0: 1$ to $2: 1 .{ }^{1} \mathrm{H}$ NMR titration spectra were obtained using a Bruker Avance $400 \mathrm{MHz}$ (9.4T) spectrometer to analyse the interaction between L-Histidine and metal ions, $\mathrm{Zn}(\mathrm{II})$ or $\mathrm{Pd}(\mathrm{II})$, with changing molar ratios. Solution spectra were measured under the following measurement conditions: $90^{\circ}$ pulse width $14 \mu s$, relaxation delay $1 \mathrm{~s}$, acquisition time 4.1 , and 32 scans at $25^{\circ} \mathrm{C}$. Chemical shifts are reported relative to the TMS by reference to the residual solvent (deuterium oxide, $\mathrm{D}_{2} \mathrm{O}$ ) peak.

\section{Electron Microscopy (TEM)}

Morphology and aggregation of different particles seen in samples, after drying, was studied with a Hitachi HT7700 TEM. Samples were prepared by dropping a dispersion of the particles onto carbon, formvar film, 300 Copper Mesh TEM grids. 


\section{RESULTS AND DISCUSSION}

The aim of this work was to explore a novel method by which to deposit a gold coating directly onto a peptide-stabilised emulsion. The first step to achieving this was to understand if alternative divalent ions to $\mathrm{Zn}$ (II) could be utilised to cross-link adjacent AM1 peptides at the oil-water interface. Specifically, palladium and platinum (II) ions were explored as they offer potential as a catalyst for the electroless deposition of a protective gold shell on the emulsion droplet surface.

\section{Stabilisation of emulsion droplets using different metal ions}

Noble metals such as palladium and platinum are known to be excellent hydrogenation/dehydrogenation catalysts, and they are often utilised as catalysts in electroless deposition reactions (Charbonnier, Alami, \& Romand, 1996; Charbonnier \& Romand, 2003; Chen, Sung, Chang, Chen, \& Ger, 2010; Dressick, Dulcey, Georger, Calabrese, \& Calvert, 1994; Hidber, Helbig, Kim, \& Whitesides, 1996; Kind, et al., 2000; Kobets \& Vorobyova, 2016; Kondo, Ishikawa, Ishida, \& Irie, 1992a, 1992b; Wang, Chen, Rubner, \& Cohen, 2001). The exact mechanism of many electroless deposition reactions remains unclear. However, it is believed that in the case of gold reduction by hydrogen peroxide, the noble metal causes decomposition of the hydrogen peroxide to produce hydroxyl radicals. These radicals trigger the reduction of chloroauric acid to gold metal. Palladium chloride is often used, in combination with tin chloride, to initiate electroless deposition of metals onto surfaces. As the AM1 peptide chelates with divalent metal ions to form a cohesive interfacial network around oil droplets, we hypothesise that substitution with palladium or platinum divalent ions would allow formation of a stable oil in water emulsion.

Initial experiments on emulsion formation using these two ions at varying concentrations were conducted using dynamic light scattering to monitor the droplet size following emulsification of $2 \%(\mathrm{v} / \mathrm{v})$ miglyol. For all emulsions, a 2:1 chelating metal ion to AM1 ratio was used, with zinc as a control. We observe little effect on emulsion droplet size by substituting the metal ion from zinc, to platinum or palladium, regardless of AM1 concentration (Figure 1a). The AM1 concentration also had limited effect on the emulsion droplet size, except for at the lowest concentration of $10 \mu \mathrm{M}$, where variable results and generally larger particles were obtained. This was likely due to inadequate surface coverage of AM1, leading to rapid de-stabilisation (Chuan, et al., 2012). Using AM1 at $200 \mu \mathrm{M}$, we 
tested the stability of the emulsions over 7 days (Figure 1b). Regardless of which chelating ion was used, the size distribution of the emulsion remained stable. These findings imply that both platinum and palladium can provide sufficient stability to the emulsion droplets by contributing to a cohesive peptide network. To further explore this, visual observations of the interface during sudden drop contraction and measurements the interfacial strength of the resulting AM1 network were conducted.
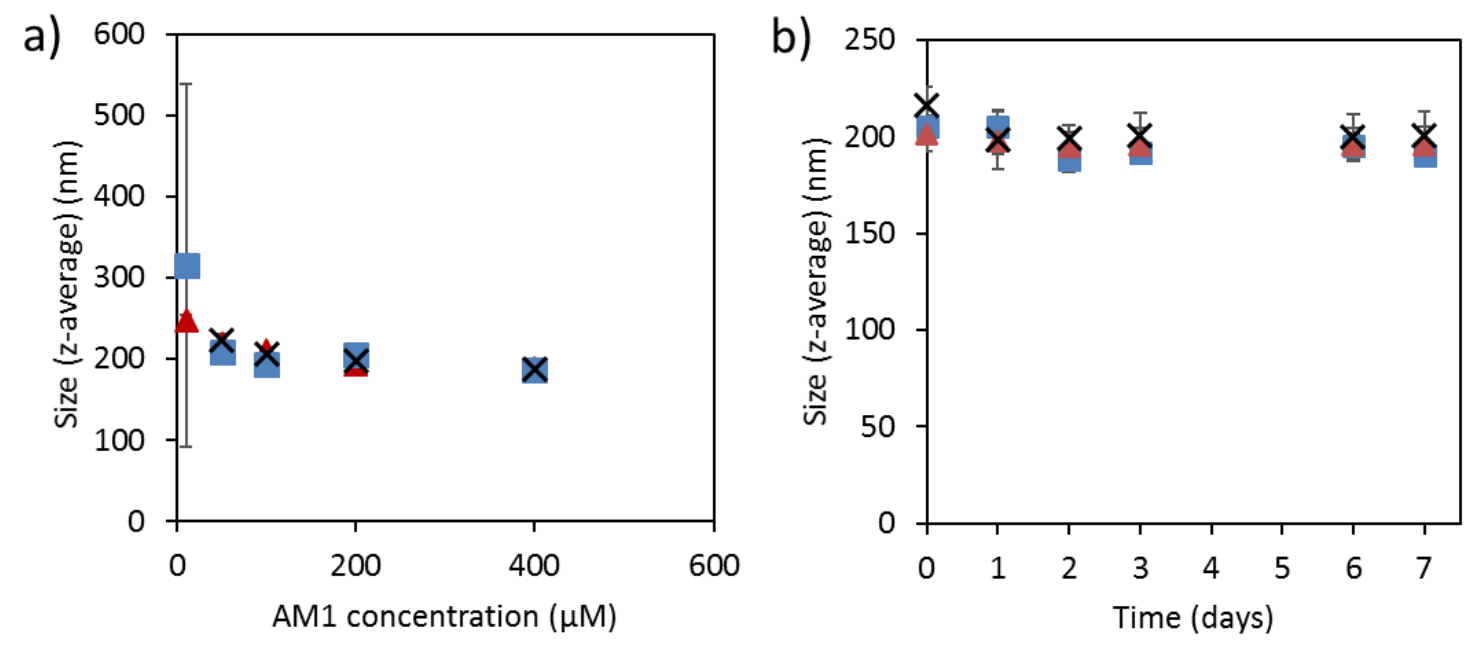

Figure 1 - Size and stability of 2\% miglyol-in-water emulsions stabilised with AM1 in the presence of different metal ions. The z-average size of AM1 emulsions coordinated to $\mathrm{Zn}$ (II) (blue square), $\mathrm{Pd}(\mathrm{II})$ (red triangle) and $\mathrm{Pt}(\mathrm{II})$ (black cross) metal ions was recorded at (a) different AM1 concentrations and (b) over time (AM1 concentration $200 \mu \mathrm{M}$ ).

\section{Effect of metal ion on the interfacial network}

Co-ordination of divalent metal ions by AM1 at the interface results in the formation of a cohesive interfacial peptide network. To verify this for $\mathrm{Pd}(\mathrm{II})$ and $\mathrm{Pt}(\mathrm{II})$, we performed droplet contraction experiments. The presence of a distorted droplet or wrinkles on the oilwater surface after droplet contraction infers elasticity of the peptide film, indicating substantial interfacial strength. Initial observations at neutral $\mathrm{pH}$ indicated that $\mathrm{Pd}(\mathrm{II})$ markedly increased surface elasticity compared to $\mathrm{Zn}$ (II) and $\mathrm{Pt}(\mathrm{II})$ (supplementary Figure S1). However, conditions for electroless deposition are highly acidic (approximately $\mathrm{pH} 2$ ) due to the presence of the chloroauric acid precursor, thus the interfacial peptide network is 
required to withstand these conditions. Therefore, droplet contraction experiments were performed under different $\mathrm{pH}$ conditions.

As Pd-AM1 qualitatively showed the greatest surface elasticity, it was chosen for further comparison with $\mathrm{Zn}-\mathrm{AM} 1$ at different $\mathrm{pH}$. Observations at shorter time points showed that in neutral conditions, both $\mathrm{Zn}(\mathrm{II})$ and $\mathrm{Pd}(\mathrm{II})$ resulted in deformation of the droplet upon contraction, with obvious wrinkles forming in the presence of $\mathrm{Pd}(\mathrm{II})$ before relaxation of the interface (Figure 2). However, under acidic conditions ( $\mathrm{pH}$ 2), the $\mathrm{Zn}$ (II) sample remained smooth and spherical post contraction indicating low interfacial elasticity and the absence of an interfacial network (Figure 2a). This corresponds to previous studies reporting a lack of interaction between histidine residues and divalent zinc ions at low $\mathrm{pH}$ (Nair, Perry, Smith, \& Reddy, 2010). Conversely, the Pd-AM1 sample exhibited high interfacial elasticity under acidic conditions.

a) $\mathrm{Zn}(\mathrm{II})$

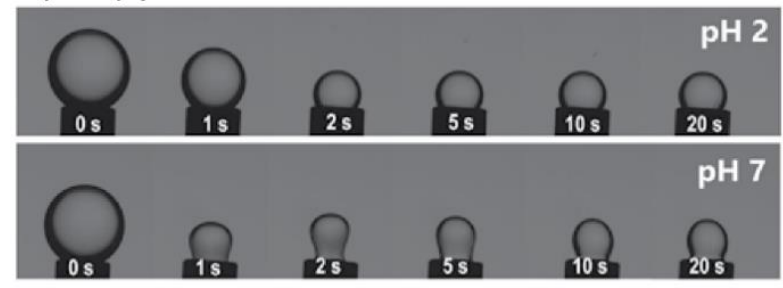

b) $\operatorname{Pd}(I I)$

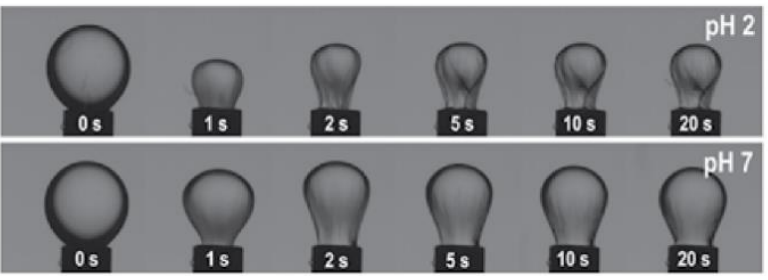

Figure 2 - Response to sudden droplet contraction of Miglyol oil droplets in $100 \mu \mathrm{M}$ AM1 solution at different $\mathrm{pH}$. Droplets were matured in the presence of (a) $\mathrm{Zn}$ (II) and (b) $\mathrm{Pd}(\mathrm{II})$.

To verify these results, Cambridge interfacial tensiometry (CIT) was used to quantify the tensile strength of the network formed at the air-water interface by AM1 with $\mathrm{Zn}$ (II) or Pd(II) (Figure 3). Negligible interfacial stress was registered with an AM1 control sample (no addition of metal chloride) after 60 minutes of expansion-compression cycles, which confirms a lack of interaction between adsorbed AM1 molecules at the air-water interface (Dexter \& Middelberg, 2007). As expected, samples of both AM1-Zn(II) and AM1-Pd(II) 
exhibited interfacial stress when strain was introduced into the system at neutral $\mathrm{pH}(\mathrm{pH} 7)$. The interfacial elasticity modulus (E) was obtained as the gradient of the linear line of best fit on the plot of the interfacial stress (mN.m-1) versus strain between $0 \%$ and $5 \%$ strain (Malcolm, Dexter, \& Middelberg, 2006). Under neutral conditions the magnitude of interfacial elasticity is stronger with $\mathrm{Zn}(\mathrm{II})(200 \mathrm{mN} / \mathrm{m})$ than $\mathrm{Pd}(\mathrm{II})(113 \mathrm{mN} / \mathrm{m})$.

In acidic conditions, CIT measurements of an AM1 film in the presence of $\mathrm{Zn}$ (II) did not produce interfacial stress, supporting the results of the contraction studies for acidic $\mathrm{pH}$. In contrast, interfacial elasticity was seen for AM1-Pd(II) under acidic conditions $(162 \mathrm{mN} / \mathrm{m})$, and a trend towards increased interfacial stress as $\mathrm{pH}$ decreases, correlates with droplet contraction (Figure 2). The stability demonstrated by the films likely reflects strong bonding between adsorbed AM1 molecules via added Pd, and suggests alternative interactions between histidine and $\mathrm{Pd}(\mathrm{II})$. As the electroless plating procedure introduces an acidic environment from addition of chloroauric acid $\left(\mathrm{HAuCl}_{4}\right)$ and $\mathrm{H}_{2} \mathrm{O}_{2}$, stability of the interface under these conditions show that $\mathrm{Pd}(\mathrm{II})$ is a suitable candidate to catalyse gold salt reduction with a view to forming a continuous gold shell. Therefore, we sought to further understand the interaction between histidine and $\mathrm{Pd}(\mathrm{II})$.

a) $\mathrm{Zn}$ (II)

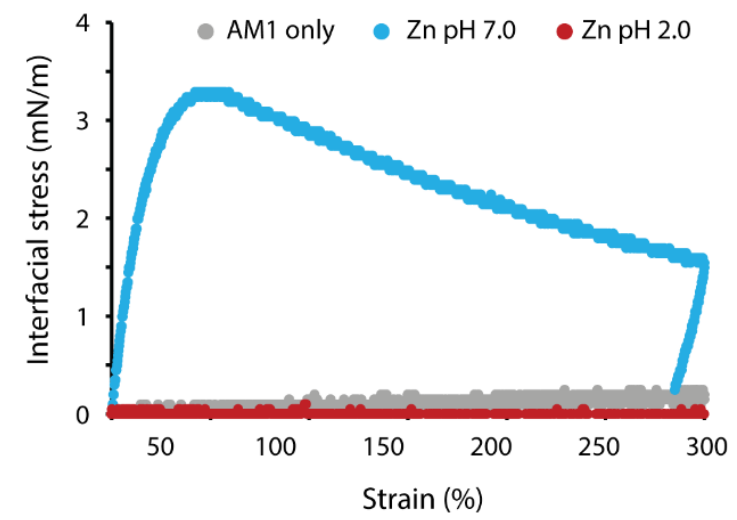

b) $\mathrm{Pd}(\mathrm{II})$

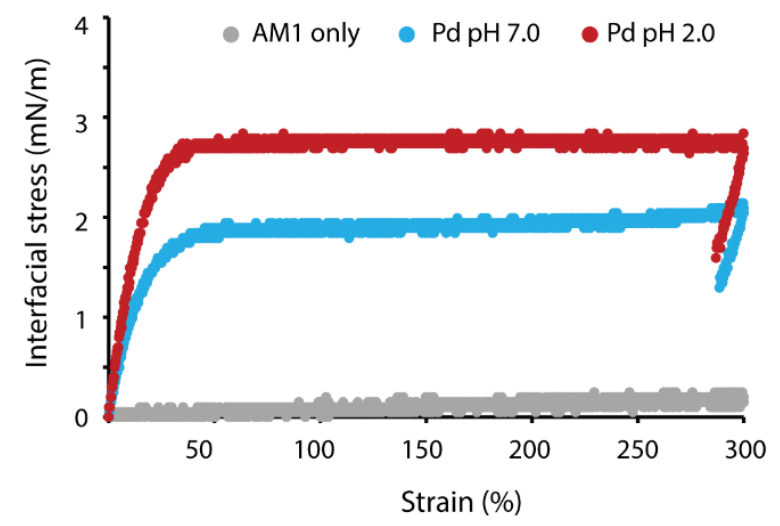

Figure 3 - Stress-strain hysteresis curves of interfacial surfactant network in response to continuous expansion and compression. Stress-strain curves were determined for $5 \mu \mathrm{M}$ solutions of AM1 (a) $\mathrm{Zn}$ (II) and (b) $\mathrm{Pd}(\mathrm{II})$ at $\mathrm{pH} 2.0$ (red) and $\mathrm{pH} 7.0$ (cyan). A control curve of AM1 with no metal ion is also shown in both panels (grey). 


\section{Interactions between metal ions and histidine}

The interactions between $\mathrm{Zn}(\mathrm{II})$ and $\mathrm{Pd}(\mathrm{II})$ metal ions and histidine residues of AM1 were examined through ${ }^{1} \mathrm{H}$ NMR of solutions of L-histidine with chloride salts of the metals. The ratio of molar concentration of the metals to histidine was varied from 0 to 2.0 , and ${ }^{1} \mathrm{H}$ NMR spectra recorded at ambient temperature. The effect of protonation of the histidine imidazole ring on interaction with the metals was probed by measurement at neutral $\mathrm{pH}$ and $\mathrm{pH} \sim 2$, well below the pKa of the imidazole ring.

Figure 4a shows the ${ }^{1} \mathrm{H}$ NMR spectra of solutions of L-histidine with various concentrations of zinc chloride in solution. The peak assignments for the protons labelled in Figure $4 \mathrm{~d}$ are shown on the lower-most spectra, and the ratio of metal to histidine listed on the right-hand side. As the concentration of $\mathrm{Zn}(\mathrm{II})$ is increased relative to the amino acid, changes are observed in the spectra. In particular, the increases in chemical shift of the imidazole protons (A and B) are evidence of the formation of complexes with the metal ions. Changes in the splitting patterns in the NMR spectra for aliphatic protons $\mathrm{C}$ and $\mathrm{D}$ are evidence of changes in conformation induced by formation of the complexes (Appleton, Pesch, Wienken, Menzer, \& Lippert, 1992). The ${ }^{1} \mathrm{H}$ NMR chemical shift for protons A and B as a function of the ratio of zinc to histidine, and shows that the chemical shifts react a plateau value at a ratio of $\mathrm{Zn}$ (II)/histidine of 0.5 (Figure 4c). It is well known that complexes of zinc and histidine are formed from two molecules of histidine binding with the metal ion, and involve participation of the unprotonated imidazole nitrogen, and amine and carboxylic acid groups of the histidine (Kretsinger, Cotton, \& Bryan, 1963). Similar results were reported by Nair and colleagues in the study of binding of various metal ions with histidine as a model of amyloid- $\beta$ proteins (Nair, et al., 2010).

The ${ }^{1} \mathrm{H}$ NMR spectra of solutions of histidine and zinc chloride at $\mathrm{pH} 2$ are shown in Figure $4 \mathrm{~b}$. Under these conditions, both of the imidazole nitrogens are protonated $(\mathrm{pKa}=$ 6.04)(Brown, 1991). The data show clearly that the NMR spectra do not change upon addition of zinc ions up to a ratio of $2: 1 \mathrm{Zn}(\mathrm{II})$ : histidine. It has been reported that protonation of the histidine imidazole prevents formation of complexes. 
(a) $\mathrm{pH} 7.5$

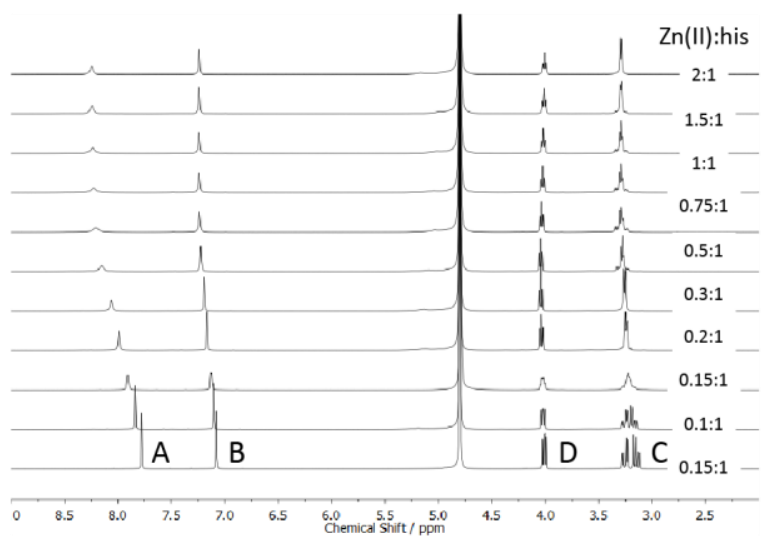

(c)

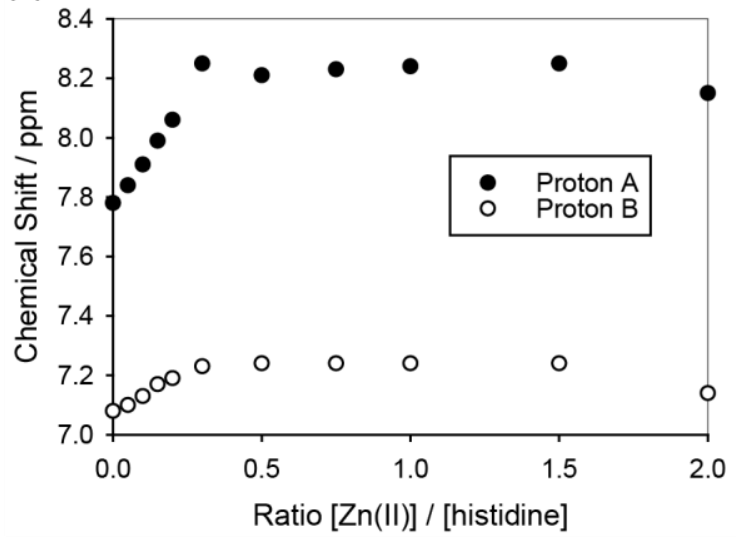

(b) $\mathrm{pH} 2.0$

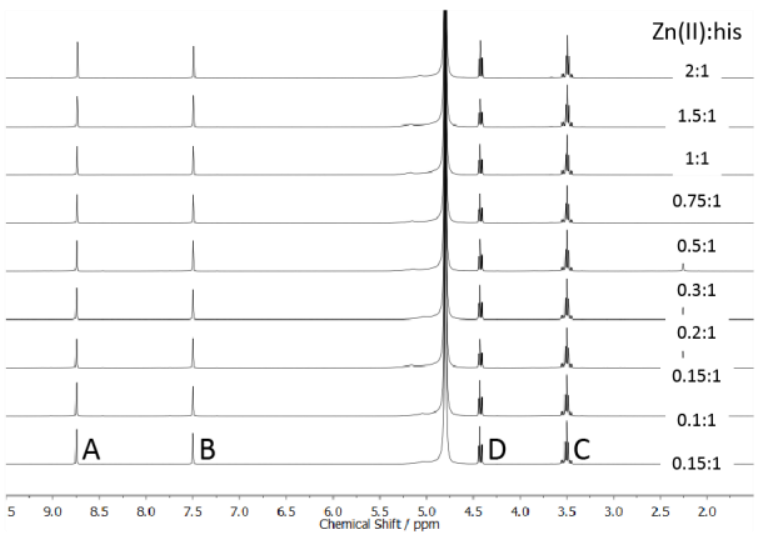

(d)

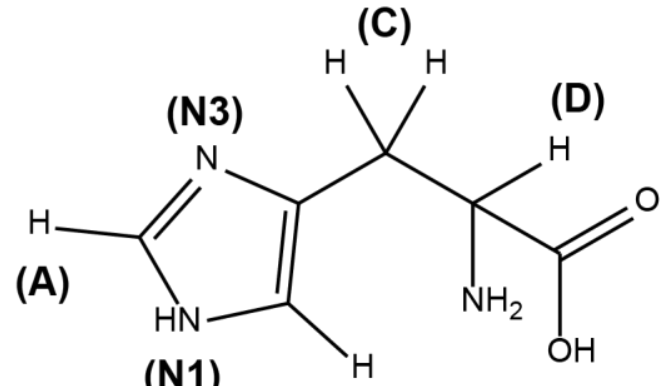

(B)

Figure $4-{ }^{1} \mathrm{H}$ NMR titration of histidine with $\mathrm{Zn}(\mathrm{II})$ in $\mathrm{D}_{2} \mathrm{O}\left(\delta^{1} \mathrm{H}\left(\mathrm{D}_{2} \mathrm{O}\right)=4.63 \mathrm{ppm}\right)$ at $25^{\circ} \mathrm{C}$ at (a) $\mathrm{pH}$ 7.5. and (b) $\mathrm{pH}$ 2.0. Molar ratio of $\mathrm{Zn}$ (II) to L-Histidine are displayed on the spectra. (c) shows the extent of chemical shift of the peaks associated with proton A and B as a function of $\mathrm{Zn}$ (II) to L-histidine ratio. (d) shows assigned peaks to the protons labelled on the L-histidine molecular structure.

The complexation of palladium ions with histidine has been examined in detail by a number of workers (Appleton, et al., 1992; Pettit \& Bezer, 1985; Tsiveriotis \& Hadjiliadis, 1999; Tsiveriotis, Hadjiliadis, \& Stavropoulos, 1997) and reviewed by Appleton some 20 years ago (Appleton, 1997). The ${ }^{1} \mathrm{H}$ NMR spectra of solutions of histidine and palladium (II) are shown in Figure5, and are substantially more complex than those with zinc salts. At higher proportions of $\mathrm{Pd}(\mathrm{II})$ to histidine, multiple signals are seen in the aromatic and aliphatic regions of the spectra. There is no clear trend of increasing chemical shift of the signals from the imidazole protons as was seen with the zinc chloride solutions, indicating that if the metal-(histidine) dimer is present it is likely in equilibrium with other species. The most complete report of the NMR spectra of palladium interactions with histidine was provided by Appleton et al. who proposed 1:1 complexes with either of the imidazole nitrogens, with 
slight preference for the complex with the nitrogen alpha to the substituent (labelled in Figure 4d as N3)(Appleton, et al., 1992). Additional species are also evident in the NMR spectra, and Appleton attributes these to dimetallic complexes of palladium bound to the amine units and to N1 or N3. As with the solutions of zinc salts, striking differences in behaviour are seen in acidic solutions of palladium salts (Figure 5b). Protons A and B of the di-protonated imidazole rings give peaks at around 8.75 and $7.5 \mathrm{ppm}$, respectively, and this uncomplexed species remains present in solution up to the highest concentration of palladium salts. However, additional species are evident in the spectra from the appearance of new, unassigned peaks at ratios of $\mathrm{Pd}(\mathrm{II})$ to histidine superior to $0.5: 1$.

(a) $\mathrm{pH} 7.5$

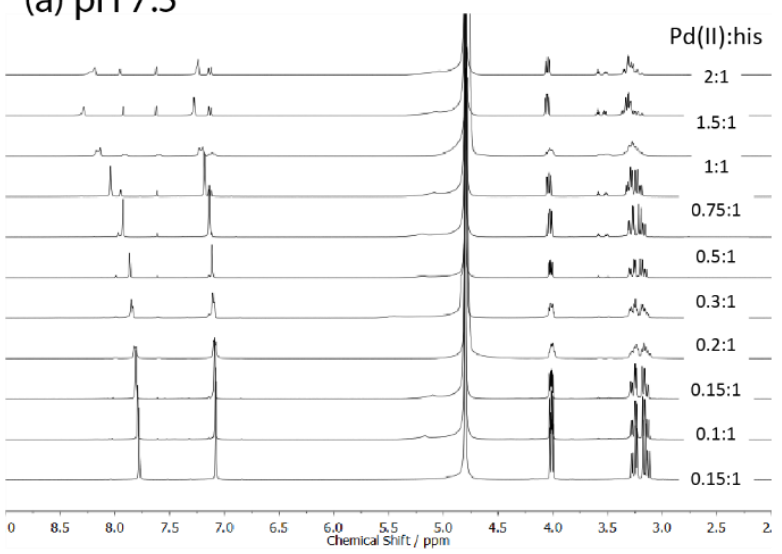

(b) $\mathrm{pH} 2.0$

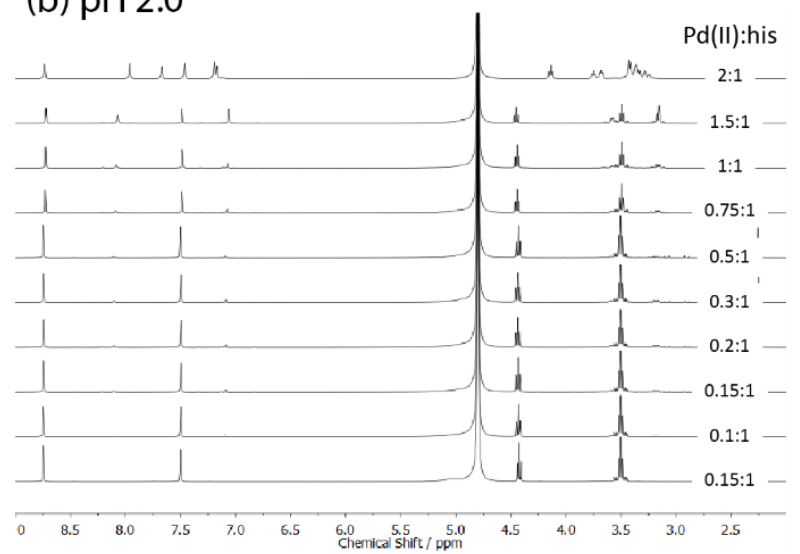

Figure $5-{ }^{1} \mathrm{H}$ NMR titration of histidine with $\mathrm{Pd}(\mathrm{II})$ in $\mathrm{D}_{2} \mathrm{O}\left(\delta^{1} \mathrm{H}\left(\mathrm{D}_{2} \mathrm{O}\right)=4.63 \mathrm{ppm}\right)$ at $25^{\circ} \mathrm{C}$ at (a) $\mathrm{pH}$ 7.5. and (b) $\mathrm{pH} 2.0$ Molar ratio of $\mathrm{Pd}(\mathrm{II})$ to L-Histidine are displayed on the spectra.

There are however limitations in comparing free histidine in bulk solution and the histidine residue on adsorbed AM1 at an interface. At the oil-water interface, the helical orientation of AM1 prevents involvement of the terminal amino and carboxyl groups from coordinating to $\mathrm{Zn}(\mathrm{II})$, thus the octahedral complex between histidine and $\mathrm{Zn}$ (II) proposed by Nair et al cannot be the case here (Nair, et al., 2010). Glutamic acid and aspartic acid residues have previously been ruled out for potential coordination to $\mathrm{Zn}$ (II), due to a lack of chemical shift variations with similar ${ }^{1} \mathrm{H}$ NMR titrations (Nair, et al., 2010). Thus, whilst $\mathrm{Zn}(\mathrm{II})$ is thought to coordinate to AM1 peptides via the two histidine residues at the oil-water interface to form a cohesive network, the exact mechanism remains unknown. Our findings with histidine suggest that $\mathrm{Pd}(\mathrm{II})$ coordinates to $\mathrm{AM} 1$ in a similar way to $\mathrm{Zn}(\mathrm{II})$ under neutral conditions, 
but is also able to coordinate in different ways, perhaps with glutamic acid and aspartic acid residues. These alternative interactions appear to dominate at low $\mathrm{pH}$.

\section{Deposition of gold onto peptide-stabilised emulsions}

The combination of the catalytic nature of palladium in gold salt reduction (supplementary Figure S2) and the ability of the Pd(II) ions to interact with the AM1 peptide to form a stable oil-water interface under acidic conditions led to $\mathrm{Pd}(\mathrm{II})$ being the ion of choice for further investigation to understand if a protective gold shell could be deposited onto the surface of the emulsion droplets. Previously, we have shown that addition of a secondary gold shell onto emulsion droplets stabilised with Pt nanoparticles allows for enhanced protection and controlled release of chemotherapeutic drugs (Hitchcock, et al., 2019). One advantage of successful deposition of a gold shell onto the AM1 stabilised emulsions is that the nanoparticles can be eliminated from the synthesis, thus removing associated toxicological concerns. There are many examples of $\mathrm{Pt}(\mathrm{II})$ complexes that are used in a therapeutic capacity (Ndagi, Mhlongo, \& Soliman, 2017). More recently Pd(II) complexes, due to their structural similarities to $\mathrm{Pt}(\mathrm{II})$ complexes, have been explored as a means by which to achieve reduced side effects with enhanced anti-tumour activity (Jahromi, et al., 2016; MansouriTorshizi, Zareian-Jahromi, Abdi, \& Saeidifar, 2018).

Figure 6 shows transmission electron microscopy images of various stages throughout the process of templating gold onto the surface of the AM1-Pd(II) emulsions. Note that, apart from Figure 6a, which shows the emulsions prior to plating, these images are not in chronological order, rather a selection of different emulsion droplets captured at 2 hours postimmersion in the electroless plating solution. From these images it appears there are two possible mechanisms of gold shell formation. The mechanism implied by Figures $6 \mathrm{~b}-\mathrm{h}$, suggests that nanoparticles of gold are forming in the bulk and subsequently migrating to the surface of the emulsion droplets over time, building up to form a particulate shell. The second possible mechanism (Figure 6f-h) is that the palladium ions, or adsorbed nanoparticles at the interface are acting as a catalyst and localising agent for the reduction to $\mathrm{Au}(0)$ at the emulsion droplet surface. This second mechanism would be more consistent with observations in our previous studies, in which metal nanoparticles have been used as the catalyst as opposed to the metal ions used in this study (Hitchcock, et al., 2019; Stark, et al., 2019; White, et al., 2019). While these images suggest the successful deposition of a gold 
shell onto the AM1-Pd stabilised emulsions, that may in fact result from a combination of the two possible mechanisms, we also noted that gold nanoparticles are also formed in the absence of AM1-Pd emulsions being added to the plating solution (supplementary Figure S3).

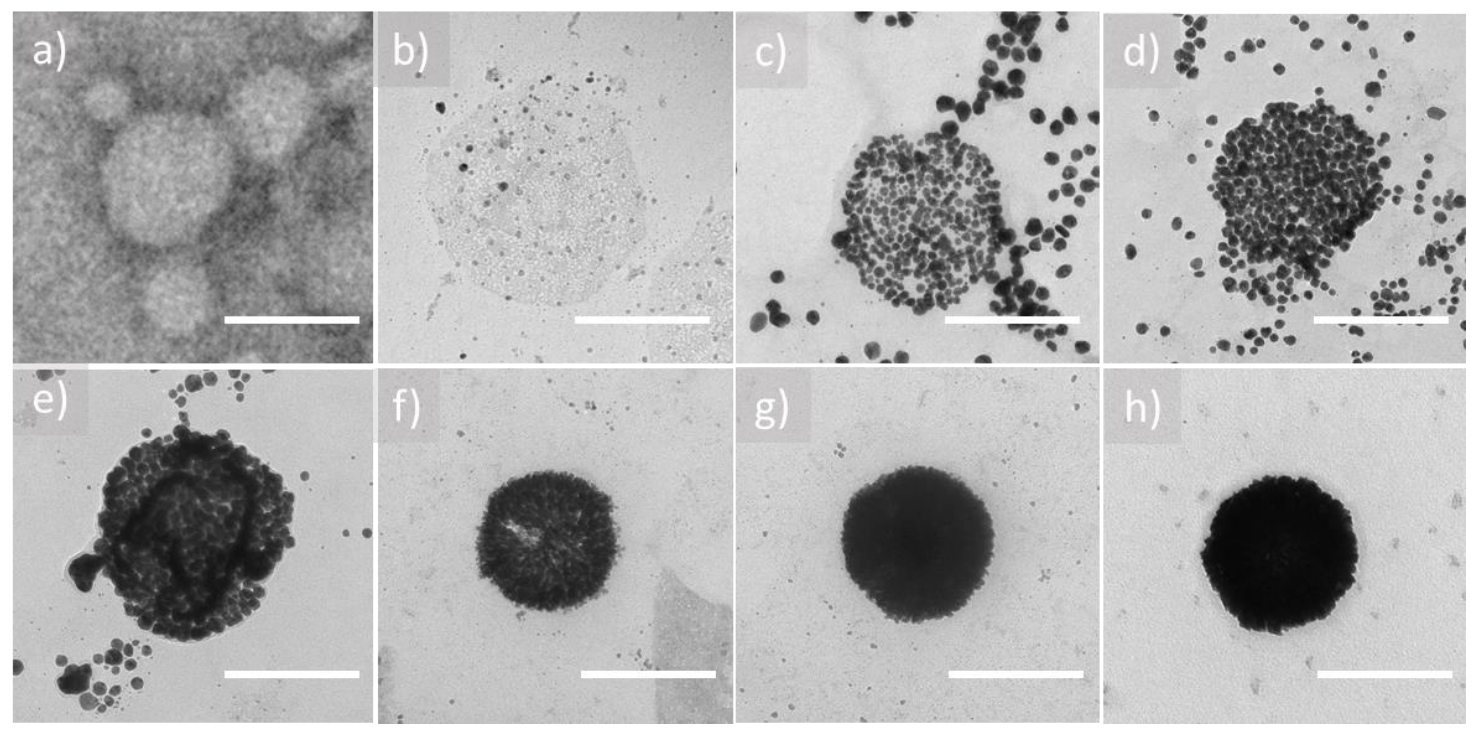

Figure 6 - TEM images of AM1-Pd-stabilised emulsions at 2 hours post-immersion in plating solution. (a) AM1-Pd-stabilised emulsion prior to plating, (b-h) emulsion droplets captured at different stages of plating. Bar $=200 \mathrm{~nm}$.

In order to further investigate the gold shell formation, we deliberately synthesised much larger $(10-50 \mu \mathrm{m})$ emulsions using an ultra-turrax homogeniser (IKA T25), and to maximise the catalytic activity at the oil-water interface, a polypeptide derivative of AM1, named DAMP4 (Middelberg \& Dimitrijev-Dwyer, 2011), comprising of four conjugated AM1 units was used to stabilise the emulsions. This modification to the stabiliser potentially allows for four times as much $\mathrm{Pd}(\mathrm{II})$ to be available at the interface to catalyse gold deposition. An oil-soluble fluorescent dye was included in the dispersed phase to enable simple determination of shell formation (Figure 7a). Figure $7 b$ and c confirms the presence of gold at the oil-water interface, using fluorescence and reflected light respectively. However, unlike in our previous work where gold shells had been successfully grown on emulsion droplets using platinum nanoparticles as the catalyst, the fluorescent signal was not completely blocked by the gold shell, suggesting that the shell was not uniform over the droplet surface. This is also apparent in the reflected light image, where some areas of the droplets appear more transparent than others. Close inspection of the droplets after drying 
onto a glass slide (Figure 7d) clearly shows that the broken shell is made up of nanoparticles as opposed to a continuous gold shell, confirming the first mechanism proposed for nanoscale formation in Figure 6. A possible explanation for this is that the availability of $\mathrm{Pd}(\mathrm{II})$ at the oil-water interface is much lower than is achieved when Pt nanoparticles are used as a Pickering stabiliser (Hitchcock, et al., 2019; White, et al., 2019) in addition to lower catalytic activity of palladium with respect to gold salt reduction (supplementary Figure S2)(Horiuchi \& Nakao, 2010). Therefore, while the stabilisation of emulsions in acidic conditions allows the deposition of a gold shell, it is not through the catalytic activity of Pd(II) at the interface. Rather, gold nanoparticles forming in bulk are allowed to absorb at the interface, forming a porous shell around the oil core.
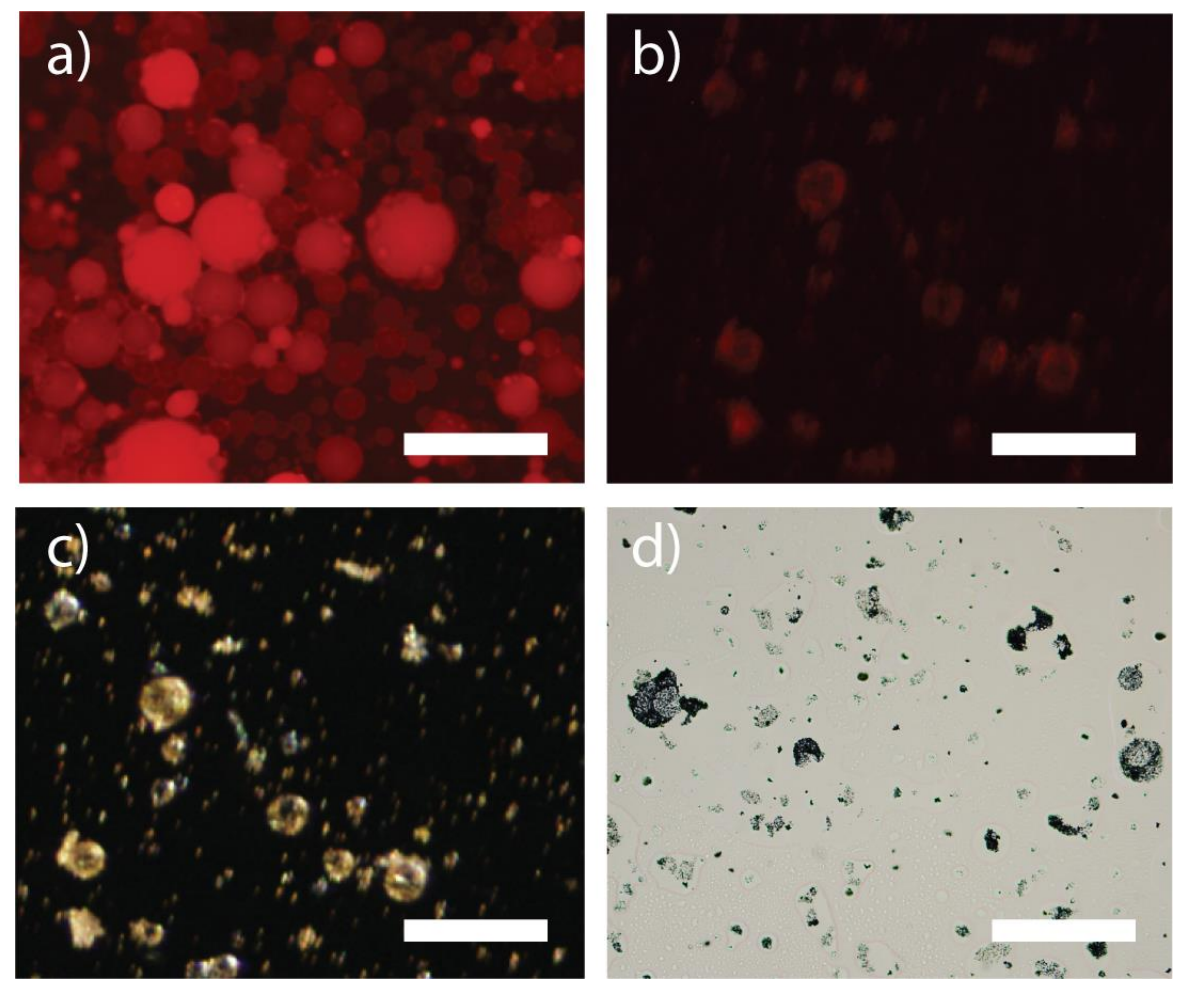

Figure 7 - Gold plating of microscale AM1-Pd-stabilised emulsions. (a) DiI-labelled emulsion prior to immersion in plating solution, (b) fluorescence image of DiI-labelled emulsion after gold plating, and (c) reflected light micrograph of DiI-labelled emulsion after gold plating. (b) and (c) are of the same field of view and the scale bar $=100 \mu \mathrm{m}$. 


\section{CONCLUSIONS}

We have successfully created a biomimetic and biocompatible emulsion template for the formation of gold shell-core particles. Using the metal ion chelating properties of the designer biosurfactant, AM1, Pd(II) ions were shown to contribute to the formation of a cohesive interfacial network to stabilise oil in water emulsions. Crucially we demonstrate that this network remained intact under acidic conditions. The interactions between $\operatorname{Pd}(\mathrm{II})$ and histidine were found to differ to the interactions between $\mathrm{Zn}$ (II) and histidine, suggesting that an alternative co-ordination mechanism of $\mathrm{Pd}(\mathrm{II})$ enables stabilisation at acidic $\mathrm{pH}$. $\mathrm{Pd}(\mathrm{II})$ ions were used as a catalyst to template a gold shell onto the emulsions, and two deposition mechanisms were proposed. However, evidence found from the drying of larger templated emulsions supports the formation of nanoparticles in the bulk which subsequently anchor to the interface to form a particulate shell. These novel core-shell particles could be useful in a wide range of applications including drug delivery, flavour and fragrance stabilisation and cosmetics or cosmeceuticals. Further work will be needed to assess their ability to retain and release cargos relevant to these application areas.

\section{ACKNOWLEDGEMENTS}

The authors acknowledge the facilities, and the scientific and technical assistance, of the Microscopy Australia Facility at the Centre for Microscopy and Microanalysis (CMM), The University of Queensland. C.X.Z acknowledges the funding support from Australian Research Council projects (FT140100726, DP150100798). A.L.W acknowledges the funding support of the CSIRO Probing Biosystems Future Science Platform.

\section{REFERENCES}

Appleton, T. G. (1997). Donor atom preferences in complexes of platinum and palladium with amino acids and related molecules. Coordination Chemistry Reviews, 166, 313-359.

Appleton, T. G., Pesch, F. J., Wienken, M., Menzer, S., \& Lippert, B. (1992). Linkage isomerism in square-planar complexes of platinum and palladium with histidine and derivatives. Inorganic Chemistry, 31, 4410-4419.

Brown, T. A. (1991). Molecular biology labfax p26: Bios Scientific/Blackwells, Oxford. 
Charbonnier, M., Alami, M., \& Romand, M. (1996). Plasma treatment process for palladium chemisorption onto polymers before electroless deposition. Journal of the Electrochemical Society, 143, 472-480.

Charbonnier, M., \& Romand, M. (2003). Polymer pretreatments for enhanced adhesion of metals deposited by the electroless process. International Journal of Adhesion and Adhesives, 23, 277-285.

Chen, W. D., Sung, Y., Chang, C. P., Chen, Y. C., \& Ger, M. D. (2010). The preparation of thermo-responsive palladium catalyst with high activity for electroless nickel deposition. Surface \& Coatings Technology, 204, 2130-2135.

Chuan, Y. P., Zeng, B. Y., O’Sullivan, B., Thomas, R., \& Middelberg, A. P. J. (2012). Codelivery of antigen and a lipophilic anti-inflammatory drug to cells via a tailorable nanocarrier emulsion. Journal of Colloid and Interface Science, 368, 616-624.

Dexter, A. F., \& Middelberg, A. P. J. (2007). Switchable Peptide Surfactants with Designed Metal Binding Capacity. The Journal of Physical Chemistry C, 111, 10484-10492.

Dexter, A. F., \& Middelberg, A. P. J. (2008). Peptides As Functional Surfactants. Industrial \& Engineering Chemistry Research, 47, 6391-6398.

Dimitrijev-Dwyer, M., He, L., James, M., Nelson, A., Wang, L., \& Middelberg, A. P. J. (2012). The effects of acid hydrolysis on protein biosurfactant molecular, interfacial, and foam properties: $\mathrm{pH}$ responsive protein hydrolysates. $8,5131$.

Dressick, W. J., Dulcey, C. S., Georger, J. H., Calabrese, G. S., \& Calvert, J. M. (1994). Covalent Binding Of Pd Catalysts To Ligating Self-Assembled Monolayer Films For Selective Electroless Metal-Deposition. Journal of the Electrochemical Society, 141, 210-220.

Gao, Y., Zhao, C. X., \& Sainsbury, F. (2021). Droplet shape control using microfluidics and designer biosurfactants. J Colloid Interface Sci, 584, 528-538.

Hidber, P. C., Helbig, W., Kim, E., \& Whitesides, G. M. (1996). Microcontact printing of palladium colloids: Micron-scale patterning by electroless deposition of copper. Langmuir, 12, 1375-1380.

Hitchcock, J., White, A. L., Hondow, N., Hughes, T. A., Dupont, H., Biggs, S., \& Cayre, O. J. (2019). Metal-shell nanocapsules for the delivery of cancer drugs. Journal of Colloid and Interface Science.

Horiuchi, S., \& Nakao, Y. (2010). Platinum colloid catalyzed etchingless gold electroless plating with strong adhesion to polymers. Surface \& Coatings Technology, 204, 38113817.

Jahromi, E. Z., Divsalar, A., Saboury, A. A., Khaleghizadeh, S., Mansouri-Torshizi, H., \& Kostova, I. (2016). Palladium complexes: new candidates for anti-cancer drugs. Journal of the Iranian Chemical Society, 13, 967-989.

Kind, H., Geissler, M., Schmid, H., Michel, B., Kern, K., \& Delamarche, E. (2000). Patterned electroless deposition of copper by microcontact printing palladium(II) complexes on titanium-covered surfaces. Langmuir, 16, 6367-6373.

Kobets, A. V., \& Vorobyova, T. N. (2016). Palladium catalyst synthesis through sol-gel processing for electroless nickel deposition on glass. Thin Solid Films, 616, 793-799.

Kondo, K., Ishikawa, F., Ishida, N., \& Irie, M. (1992a). Photochemical Deposition Of Pd(0) From Adsorbed Pd(II)-Complex Ions. Journal of the Electrochemical Society, 139, 2815-2817.

Kondo, K., Ishikawa, F., Ishida, N., \& Irie, M. (1992b). Photoreductive Deposition Of Palladium For Electroless Copper Plating. Chemistry Letters, 999-1002.

Kretsinger, R. H., Cotton, F. A., \& Bryan, R. F. (1963). The crystal and molecular structure of di-(L-histidine)-zinc(II) dihydrate. Acta Crystallographica, 16, 651-657. 
Leleux, J., \& Roy, K. (2013). Micro and Nanoparticle-Based Delivery Systems for Vaccine Immunotherapy: An Immunological and Materials Perspective. Advanced Healthcare Materials, 2, 72-94.

Malcolm, A. S., Dexter, A. F., \& Middelberg, A. P. J. (2006). Foaming properties of a peptide designed to form stimuli-responsive interfacial films. 2, 1057.

Malcolm, A. S., Dexter, A. F., \& Middelberg, A. P. J. (2007). Peptide surfactants (Pepfactants) for switchable foams and emulsions. Asia-Pacific Journal of Chemical Engineering, 2, 362-367.

Mansouri-Torshizi, H., Zareian-Jahromi, S., Abdi, K., \& Saeidifar, M. (2018). Nonionic but water soluble, [Glycine-Pd-Alanine] and [Glycine-Pd-Valine] complexes. Their synthesis, characterization, antitumor activities and rich DNA/HSA interaction studies. Journal of Biomolecular Structure and Dynamics, 1-46.

Mason, T. G., Wilking, J. N., Meleson, K., Chang, C. B., \& Graves, S. M. (2006). Nanoemulsions: formation, structure, and physical properties. Journal of Physics: Condensed Matter, 18, R635-R666.

Middelberg, A. P. J., \& Dimitrijev-Dwyer, M. (2011). A Designed Biosurfactant Protein for Switchable Foam Control. 12, 1426-1429.

Nair, N. G., Perry, G., Smith, M. A., \& Reddy, V. P. (2010). NMR studies of zinc, copper, and iron binding to histidine, the principal metal ion complexing site of amyloid-beta peptide. J Alzheimers Dis, 20, 57-66.

Ndagi, U., Mhlongo, N., \& Soliman, M. (2017). Metal complexes in cancer therapy \&ndash; an update from drug design perspective. Drug Design, Development and Therapy, Volume 11, 599-616.

Nocera, G. M., Ben M'Barek, K., Bazzoli, D. G., Fraux, G., Bontems-Van Heijenoort, M., Chokki, J., Georgeault, S., Chen, Y., \& Fattaccioli, J. (2014). Fluorescent microparticles fabricated through chemical coating of $\mathrm{O} / \mathrm{W}$ emulsion droplets with a thin metallic film. RSC Advances, 4, 11564.

Pettit, L. D., \& Bezer, M. (1985). Complex formation between palladium(II) and amino acids, peptides and related ligands. Coordination Chemistry Reviews, 61, 97-114.

Rosenblum, L. T., Kosaka, N., Mitsunaga, M., Choyke, P. L., \& Kobayashi, H. (2010). In vivo molecular imaging using nanomaterials: General in vivo characteristics of nano-sized reagents and applications for cancer diagnosis (Review). Molecular Membrane Biology, 27, 274-285.

Sainsbury, F., Zeng, B., \& Middelberg, A. P. (2014). Towards designer nanoemulsions for precision delivery of therapeutics. Current Opinion in Chemical Engineering, 4, 11-17.

Simms, R. W., Kim, D. H., Weaver, D. M., Sundararajan, C., Blacker, M., Stephenson, K. A., \& Valliant, J. F. (2012). Emulsion Reactors: A New Technique for the Preparation of Molecular Imaging Probes. Chemistry - A European Journal, 18, 6746-6749.

Sonneville-Aubrun, O., Yukuyama, M. N., \& Pizzino, A. (2018). Application of Nanoemulsions in Cosmetics. In (pp. 435-475): Elsevier.

Stark, K., Hitchcock, J. P., Fiaz, A., White, A. L., Baxter, E. A., Biggs, S., McLaughlan, J. R., Freear, S., \& Cayre, O. J. (2019). Encapsulation of Emulsion Droplets with Metal Shells for Subsequent Remote, Triggered Release. ACS Applied Materials \& Interfaces, 11, 12272-12282.

Tayeb, H. H., Piantavigna, S., Howard, C. B., Nouwens, A., Mahler, S. M., Middelberg, A. P. J., He, L., Holt, S. A., \& Sainsbury, F. (2017). Insights into the interfacial structurefunction of poly(ethylene glycol)-decorated peptide-stabilised nanoscale emulsions. Soft Matter, 13, 7953-7961.

Tayeb, H. H., \& Sainsbury, F. (2018). Nanoemulsions in drug delivery: formulation to medical application. Nanomedicine (Lond), 13, 2507-2525. 
Tayeb, H. H., Stienecker, M., Middelberg, A. P. J., \& Sainsbury, F. (2019). Impact of SiteSpecific Bioconjugation on the Interfacial Activity of a Protein Biosurfactant. Langmuir, 35, 13588-13594.

Tsiveriotis, P., \& Hadjiliadis, N. (1999). Studies on the interaction of histidyl containing peptides with palladium(II) and platinum(II) complex ions. Coordination Chemistry Reviews, 190-192, 171-184.

Tsiveriotis, P., Hadjiliadis, N., \& Stavropoulos, G. (1997). NMR study of the interaction of platinum(II) and palladium(II) complex ions with His-Ala and His-Gly-Ala. Inorganica Chimica Acta, 261, 83-92.

Velikov, K. P., \& Pelan, E. (2008). Colloidal delivery systems for micronutrients and nutraceuticals. 4, 1964.

Wang, T. C., Chen, B., Rubner, M. F., \& Cohen, R. E. (2001). Selective electroless nickel plating on polyelectrolyte multilayer platforms. Langmuir, 17, 6610-6615.

White, A. L., Langton, C., Wille, M.-L., Hitchcock, J., Cayre, O. J., Biggs, S., Blakey, I., Whittaker, A. K., Rose, S., \& Puttick, S. (2019). Ultrasound-triggered release from metal shell microcapsules. Journal of Colloid and Interface Science, 554, 444-452.

Wibowo, D., Zhao, C.-X., \& Middelberg, A. P. J. (2014). Emulsion-templated silica nanocapsules formed using bio-inspired silicification. Chemical Communications, 50, 11325.

Yamada, M., Tayeb, H., Wang, H., Dang, N., Mohammed, Y. H., Osseiran, S., Belt, P. J., Roberts, M. S., Evans, C. L., Sainsbury, F., \& Prow, T. W. (2018). Using elongated microparticles to enhance tailorable nanoemulsion delivery in excised human skin and volunteers. J Control Release, 288, 264-276.

Zeng, B. J., Chuan, Y. P., O'Sullivan, B., Caminschi, I., Lahoud, M. H., Thomas, R., \& Middelberg, A. P. J. (2013). Receptor-Specific Delivery of Protein Antigen to Dendritic Cells by a Nanoemulsion Formed Using Top-Down Non-Covalent Click SelfAssembly. Small, 9, 3736-3742. 


\section{Templating core-shell particles using metal ion-chelating biosurfactants}

Ching-min Yeh ${ }^{1,2}$; Thomas Jarrett ${ }^{1}$; Yuan $\mathrm{Gao}^{1}$;; Chunxia Zhao ${ }^{1}$; Andrew Whittaker ${ }^{1,2}$, Frank Sainsbury ${ }^{1,4}$; Alison L. White ${ }^{1,2,3 *}$

1. Australian Institute of Bioengineering and Nanotechnology, The University of Queensland, St. Lucia, Queensland, 4072, Australia.

2. ARC Centre of Excellence in Convergent Bio-Nano Science and Technology, The University of Queensland, St Lucia, 4072, Australia

3. CSIRO Probing Biosystems Future Science Platform, Brisbane, Australia

4. Centre for Cell Factories and Biopolymers, Griffith Institute for Drug Discovery, Griffith University, Brisbane, QLD, 4111 Australia

Supplementary Information:

Figure S1 - Droplet contraction of AM1 in the presence of different divalent cations.

Figure S2 - Catalytic activity of metal ions with respect to reduction of $\mathrm{Au}$ (III) to $\mathrm{Au}(0)$.

Figure S3 - Precipitation of gold particle in the ELP solution. 
AM1

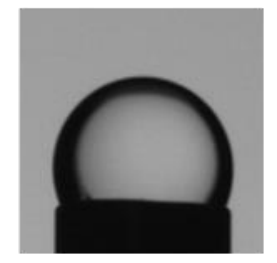

Zn-AM1

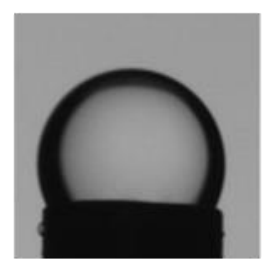

Pd-AM1

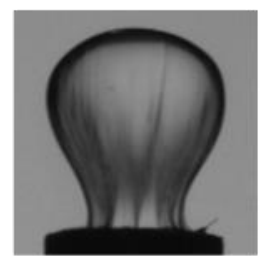

Pt-AM1

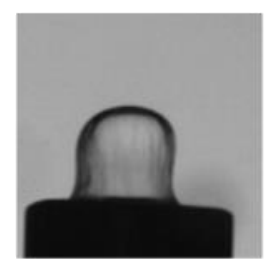

Figure S1 - Droplet contraction of AM1 in the presence of different divalent cations. Photographs of contracted droplets stabilised by a) AM1 alone, or co-ordinated to b) Zn(II), c) Pd(II) and d) Pt(II). Droplet contraction occurred 30 minutes after pendant drop formation

Figure S1 depicts visual differences in contracted droplet surface and shape, at neutral $\mathrm{pH}$, for the different co-ordinating metal ions in addition to AM1 alone. The images show droplets 10 seconds post contraction. Obvious wrinkles are visible for Pd-AM1 and Pt-AM1, although co-ordination with Pd ions appears to provide a stronger interfacial network as compared to Pt ions, where the droplet has deformed. In the case of Zn-AM1, the droplet has held its shape more than AM1 alone, although wrinkling to indicate a strong interfacial network is not observed. The interfacial network created when $\mathrm{Zn}$ is used as the coordinating ion can be more clearly observed in figure 3a, between 2 and 5 seconds, where the pendant shape of the droplet is retained for a short period of time. 


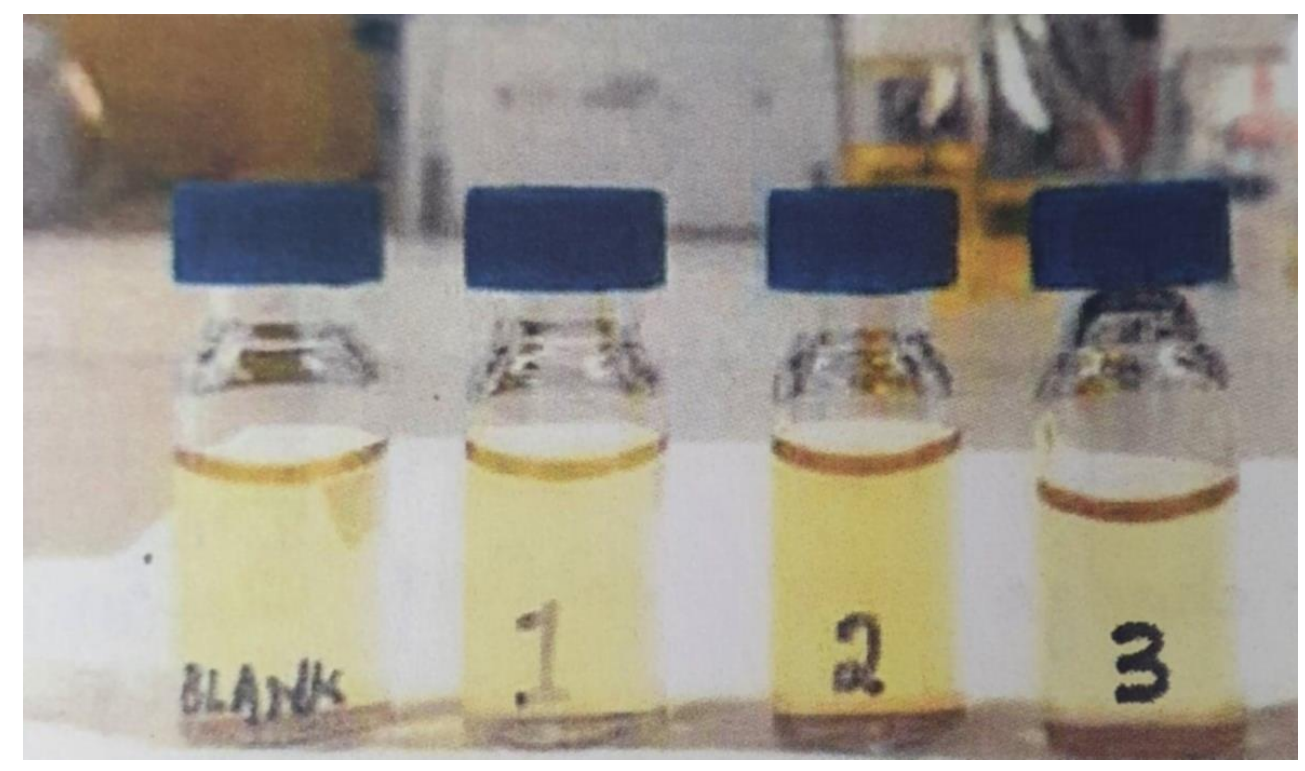

Figure S2 - Photograph showing catalytic activity of metal ions with respect to reduction of $\mathrm{Au}$ (III) to $\mathrm{Au}(0)$, using hydrogen peroxide as the reducing agent, L-R blank (no metal ion), 1) Zn(II), 2) Pd(II), and 3) $\mathrm{Pt}(\mathrm{II})$ at $\mathrm{t}=2$ hours.

Figure $\mathrm{S} 2$ shows the catalytic ability of different metal ions in the reduction of $\mathrm{Au}(\mathrm{III})$ to $\mathrm{Au}(0)$. From the image sedimented $\mathrm{Au}(0)$ particles are clearly visible when $\mathrm{Pd}(\mathrm{II})$ and $\mathrm{Pt}(\mathrm{II})$ ions were used as the catalyst. A lack of precipitated gold is evident for the blank, with no metal ions added, and also for $\mathrm{Zn}(\mathrm{II})$ ions over the reaction time of 2 hours. 

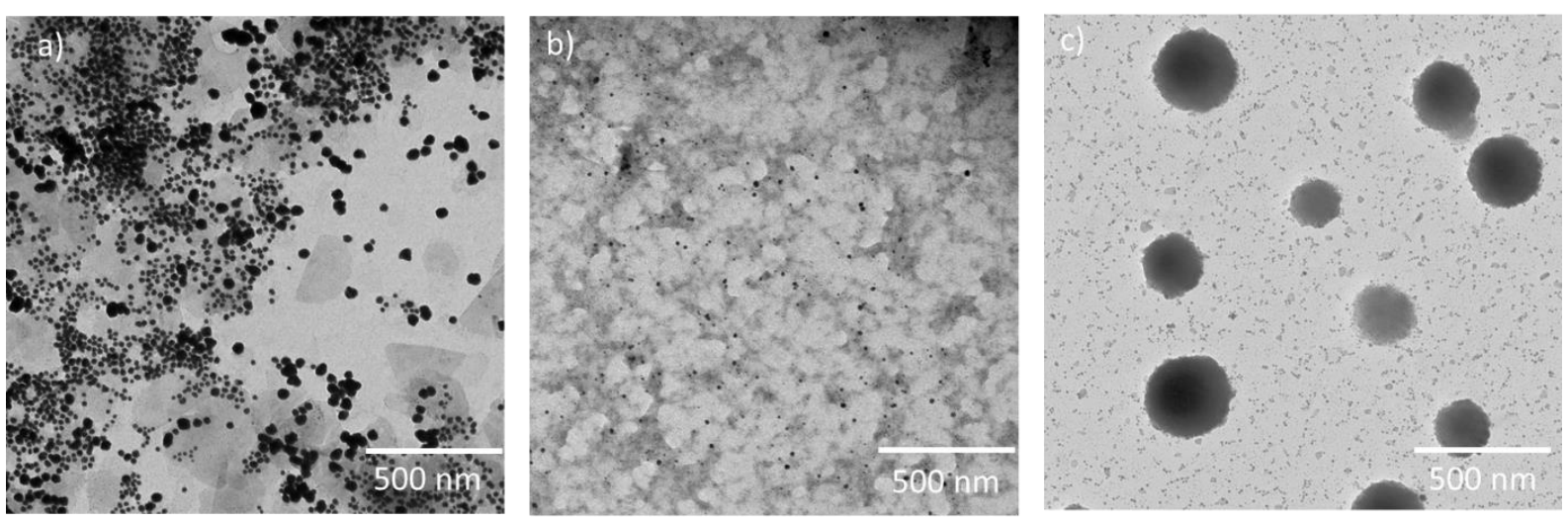

Figure S3 - Precipitation of gold particle in the ELP solution.

As can be observed in figure 7a and $b$, particulate gold nanoparticles are formed even when no emulsion, and therefore Pd catalyst, was added to the electroless plating solution. Figure 7a shows spherical nanoparticles of up to $100 \mathrm{~nm}$ are formed when gold salt and poly(vinyl pyrollidone), used as a colloidal stabiliser in our procedure, are mixed for 1 hour. This is likely due to the polymer acting as a weak reducing agent over such timeframes, due to the terminal hydroxyl groups. ${ }^{1} \mathrm{PVP}$ has been used as a reducing agent to form $\mathrm{Pd}$ and $\mathrm{Ag}$ nanoparticles, with the size and shape of the particles being controlled by the concentration and therefore number of available terminal hydroxyl groups. ${ }^{2-}$ ${ }^{4}$ In figure $7 \mathrm{~b}$ however, when hydrogen peroxide is added to the reagents, the resulting nanoparticles are much smaller in diameter, and are easily distinguishable from the coated emulsions (figure 7c). This is likely due to an increase in nucleation rate, ${ }^{5}$ with hydrogen peroxide being a stronger reducing agent than PVP, and thus the formation of smaller particles which remain stable due to the presence of the PVP. 


\section{References:}

1. Koczkur, K. M.; Mourdikoudis, S.; Polavarapu, L.; Skrabalak, S. E., Polyvinylpyrrolidone (PVP) in nanoparticle synthesis. Dalton Transactions 2015, 44 (41), 17883-17905.

2. Huang, X.; Zheng, N., One-Pot, High-Yield Synthesis of 5-Fold Twinned Pd Nanowires and Nanorods. Journal of the American Chemical Society 2009, 131 (13), 4602-4603.

3. Lim, B.; Jiang, M.; Tao, J.; Camargo, P. H. C.; Zhu, Y.; Xia, Y., Shape-Controlled Synthesis of Pd Nanocrystals in Aqueous Solutions. Advanced Functional Materials 2009, 19 (2), 189-200.

4. Washio, I.; Xiong, Y.; Yin, Y.; Xia, Y., Reduction by the End Groups of Poly(vinyl pyrrolidone): A New and Versatile Route to the Kinetically Controlled Synthesis of Ag Triangular Nanoplates. Advanced Materials 2006, 18 (13), 1745-1749.

5. Li, Q.; Lu, B.; Zhang, L.; Lu, C., Synthesis and stability evaluation of size-controlled gold nanoparticles via nonionic fluorosurfactant-assisted hydrogen peroxide reduction. Journal of Materials Chemistry 2012, 22 (27), 13564. 